\title{
PENGGUNAAN MEDIA CELEMEK PINTAR DALAM MENINGKATKAN KEMAMPUAN MENGENAL HURUF HIJAIYAH ANAK USIA 3-4 TAHUN DI KELOMPOK BERMAIN AISYIYAH TENGGARONG TAHUN AJARAN 2018/2019
}

\author{
Sri Syahadah \\ PG PAUD Universitas Widya Gama Mahakam Samarinda \\ srisyahadah@gmail.com \\ Hanita \\ PG PAUD Universitas Widya Gama Mahakam Samarinda \\ nitahanita87@gmail.com
}

\begin{abstract}
Abstrak
PAUD is an act of providing stimulation as a stimulation to children aged 0-6 years, to achieve maximum growth and development. This was done both and so that the child will be ready to enter the next level of education. To achieve growth and development, it is necessary to develop aspects of cognitive abilities, language, motor skills, arts, social, emotional, religious values, through fun activities. Religious values are developed through Imtaq, hoping children will recognize, know, understand and say Hijaiyah as a developing ability for children to recite as a benchmark for achieving child development. The purpose of this study was to determine the use of Smart Apron Media in improving the ability to recognize letters Hijaiyah Children Age 3-4 Years in the Play Group Aisyiyah Tenggarong, 2019. This research was PTK (Classroom Action Research). This research was carried out with two cycles in which each cycle consisted of 4 (four) stages that had to be passed planning, implementation, observation, and reflection. The subjects of this study were 10 children comprising 4 boys and 6 girls. While the object of this research is the use of smart apron media in improving the ability to recognize Hijaiyah letters. Data collection techniques used are observation and documentation. Based on the results of research in the first cycle, for meetings 1 and 2 have seen an increase of $45 \%$ and at the second meeting reached $70 \%$. in the second cycle the first meeting achieved an increase with 72 percent and in the second meeting reached $85 \%$. The results be concluded that by using smart apron media the ability to recognize letters of Hijaiyah as a whole has experienced a good increase in every aspect of its assessment.
\end{abstract}

Keywords: Understanding Hihayah Letter 


\section{Pendahuluan}

Tujuan Pendidikian Nasional, yaitu ingin mencerdaskan kehidupan bangsa dan mengembangkan manusia Indonesia seutuhnya, yaitu membentuk manusia yang beriman dan bertaqwa terhadap Tuhan Yang Maha Esa dan berbudi pekerti luhur, memiliki pengetahuna dan keterampilan, kepribadian yang matang, baik secara jasmani dan rohaninya. Yang tertuang dalam UU.No.20 Tahun 2003. Pasal 3.

Untuk mencapai tujuan itu maka perlu suatu langkah awal dengan memberikan pendidikan kepada anak usia dini, Pendidikan Anak Usia Dini (PAUD) sebagai tiang utama agar memiliki generasi yang berkarakter dan mampu terampil. PAUD merupakan suatu tindakan pemberian rangsangan sebagai stimulasi kepada anak usia 0-6 tahun, untuk dapat mencapai pertumbuhan dan perkembangannya secara maksimal, baik jasmani dan rohaninya sehingga anak akan siap memasuki jenjang pendidikan selanjutnya, sesuai tujuan anak usia dini. Usia dini merupakan usia emas bagi anak usia 0-6 tahun, masa ini adalah masa berharga bagi anak untuk tumbuh dan berkembang baik secara fisik maupun intelektualnya, kemampuan kognitif, bahasa, motorik, seni, sosial emosional, nilai-nilai agama dan moral, yang dapat menjadi bekal bagi anak untuk memasuki jenjang pendidikan selanjutnya, sudah tentu peran orang dewasa sangat diperlukan sebagai pendukung anak mencapai perkembangannya, yaitu orang tua dan pendidik.

\section{METODE PENELITIAN}

\section{Jenis Penelitian}

Penelitian ini merupakan penelitian tindakan kelas (classroom action research) yang dilakukan secara kolaboratif dan partisipatif. Suyanto mendefinisikan PTK sebagai suatu bentuk penelitian yang bersifat reflektif, dengan melakukan tindakan-tindakan tertentu agar dapat memperbaiki dan atau meningkatkan praktik pembelajaran di kelas secara professional.

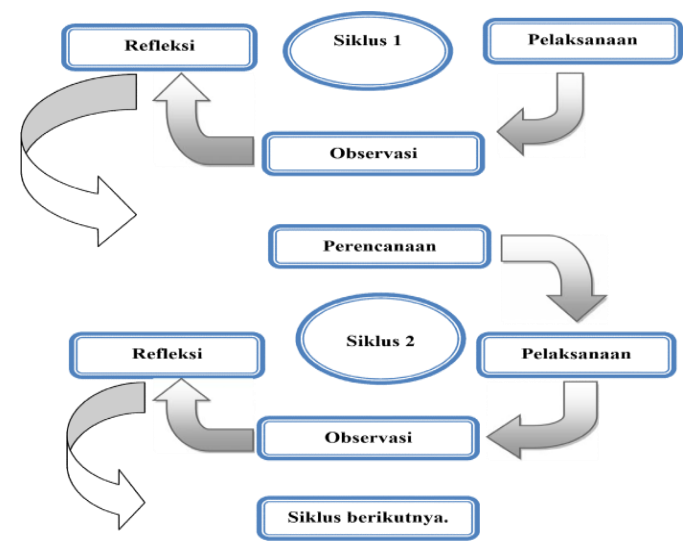

Gambar 3.1.

Bagan Teknis Desain Siklus Penelitian

Suharsimi ( Arikunto, 2011:16 )

Waktu Penelitian

Penelitian tindakan kelas dilakukan pada semester II pada Bulan Maret - April 2019 tahun pelajaran 2018/2019, pada yang dilaksanakan pada waktu pembelajaran berlangsung dari pukul $07.30-10.30$ wita. Tempat Penelitian

Tempat penelitian tindakan kelas yang di lakukan peneliti adalah Kelompok Bermain Aisyiyah Tenggarong, Jl. Danau Aji, Gg. Wakab, Kel. Melayu. Tenggarong. 
Kabupaten Kutai Kartanegara

\section{Subyek Penelitian}

Subyek penelitian tindakan kelas adalah anak didik pada Kelompok Bermain Aisyiyah Tenggarong, yang berjumlah 10 anak. Terdiri dari 6 anak perempuan dan 4 anak laki-laki.

\section{Prosedur Penelitian.}

Prosedur penelitian tindakan kelas di Kelompok Bermain Aisyiyah tenggarong, dalam Penggunaan media celemek pintar, dalam meningkatkan kemampuan mengenal huruf hijaiyah anak usia 3-4 tahun, dengan melalui tiga tahap yaitu melalui perencanaan, pelaksanaan, observasi dan refleksi. Instrumen Penilaian Instrumen penilaian sebagai pendukung untuk mendapatkan data dalam penelitian ini adalah;

Lembar Observasi

Lembar observasi digunakan sebagai pedoman untuk melakukan pengamatan yang berbentuk check list. Check List adalah lembar yang memuat daftar variable yang akan dikumpulkan datanya, dan peneliti hanya tinggal memberikan tanda centang pada pemunculan kemampuan yang dicapai anak dalam kemampuan mengenal huruf hijaiyah. Adapun indikator kemampuan mengenal huruf hijaiyah anak yaitu sesuai dengan table berikut ;
Table .Kisi-kisi Standar kemampuan mengenal huruf hijaiyah

\begin{tabular}{|c|l|}
\hline No & \multicolumn{1}{|c|}{ Indikator Penilaian } \\
\hline 1 & u Mengenal Bentuk Huruf Hijaiyah \\
\hline 2 & $\begin{array}{l}\text { Anak Mampu Mengenal dan Tahu Bunyi } \\
\text { Huruf Hijaiayh }\end{array}$ \\
\hline 3 & $\begin{array}{l}\text { Anak Mampu Mencari Huruf Hijaiyah } \\
\text { sesuai Gambar }\end{array}$ \\
\hline 4 & $\begin{array}{l}\text { Anak Mampu Melengkapi Huruf Hijaiyah } \\
\text { sesuai Gambar }\end{array}$ \\
\hline
\end{tabular}

Teknik dan Alat Pengumpulan Data

Tehnik pengumpulan data

Dalam penelitian ini, peneliti menggunakan tehnik observasi. Observasi dilakukan untuk mengamati anak secara langsung saat proses kegiatan mengajar. Guru sebagai peneliti tindakan kelas harus mengobservasi atau mengamati proses tindakannya secara teliti dan cermat.

Alat pengumpulan data

Dalam penelitian ini, peneliti menggunakan alat pengumpulan data yaitu: a. Lembar Observasi

Lembar observasi terdiri dari hal-hal yang akan diteliti oleh peneliti yang menyangkut tentang kegiatan pembelajaran untuk melihat sejauh mana peningkatan dalam mengenal huruf hijaiyah pada anak.

a. Dokumentasi.

Dokumentasi merupakan sumber guna mendapatkan data otentik yang dikumpulkan sebagai bahan untuk dianalisis baik secara tertulis maupun gambar (Foto), dokumentasi yang digunakan peneliti sebagai penilaian dari hasil belajar anak dalam peningkatan kemampuan mengenal huruf hijaiyah, yang dapat dilihat dari lembar observasi dan foto saat kegiatan berlangsung sebagai alat 
pengambil keputusan.

\section{Analisis Data}

Dalam penelitian tindakan kelas ini peneliti menggunakan analisis data diskriptif:

1. Observasi dengan cara mengamati kegiatan anak secara langsung dalam proses kegiatan pengunaan media cemelek pintar dalam meningkatkan kemampuan mengenal huruf hijaiyah dengan menggunakan analisis diskriptif kualitatif.

2. Hasil belajar dianalisis dengan menggunakan analisis diskriptif komparatif yaitu kegiatan tanya jawab dengan siklus maupun indikator.

Teknik analisis data disesuaikan dengan datanya. Pada umumnya data berbentuk kuantitatif dianalisis dengan analisis diskriptip komparatif, yaitu membandingkan data kuantitatif dari kondisi awal, siklus I, siklus II dan siklus III dengan rumus, nilai rata-rata hasil belajar anak dapat dihitung dengan menggunakan rumus sebagai berikut

$X=X \quad x 100 \% N$

Keterangan :

$\mathrm{X}=$ Nilai rata-rata $=$ Jumlah semua nilai siswa

$\mathrm{N}=$ Jumlah siswa

Aqib,dkk ( 2008; 40 ).

Setelah semua data dianalisis dengan rumus persentasi tersebut, maka peneliti memberikan indikator keberhasilan pengunaan media celemek pintar dalam meningkatkan kemampuan mengenal huruf hijaiyah anak sesuai dengan kemampuan yang dimiliki setiap anak sebagai kemapuan perkembangan kemampuan mengenal huruf hijaiyah.

Adapun rumusan yang digunakan untuk menganalisis data guna memperoleh hasil dari Penelitian yang dilakukan, sebagai berikut:

1. Jumlah skor yang diperoleh pada penilaian kemampuan menyimak dan mengikuti lafal huruf hijiyah, mampu mengulang lafal huruf hijaiyah dengan tepat.menunjukkan huruf hijaiyah dengan benar, mampu menggabungkan huruf hijaiyah dengan gambar

2. Menghitung jumlah kemampuan menyimak dan mengikuti lafal huruf hijiyah, mampu megulang lafal huruf hijaiyah dengan tepat.menunjukkan huruf hijaiyah dengan benar, mampu menggabungkan huruf hijaiyah dengan gambar

3. Menghitung prentase kamampuan mengenal huruf hijaiyah.

\section{Indikator Keberhasilan}

Tindakan dinyatakan berhasil dalam penelitian ini apabila jumlah anak yang telah mencapai kemampuan mengenal huruf hijaiyah mencapai $80 \%$ dengan kriteria keberhasilan Berkembang Sangat Baik ( BSB ) dibanding dengan yang mencapai Berkembang Sesuai Harapan (BSB), Mulai Berkembang (MB) dan Belum Berkembang (BB). 


\section{HASIL DAN PEMBAHASAN}

\section{Hasil Penelitian}

Hasil penelitian Pelaksanaan penelitian tindakan kelas pada anak KB. Aisiyah Tenggarong dilaksanakan dengan 2 (dua) siklus yaitu siklus I, dan siklus II. Pada pelaksanaan tindakan siklus penelitian terdiri dari 4 (empat) tahapan yaitu, tahap perencanaa, tahap pelaksanaan, tahap observasi dan tahap refleksi.

a. Siklus I

Hasil dari setiap aspek penilaian pada siklus I pertemuan I di KB. Aisiyah Tenggarong pada Kelompok Besar dengan jumlah murid 10 anak. Pada aspek kemampuan anak mengenal bentuk huruf hijaiyah dengan media celemek pintar, 5 (lima) anak (50\%) yang mendapat nilai BSH, dan 5 (lima) anak (50\%) mendapat nilai MB.

Pada aspek penilaian kemampuan anak dalam mengenal dan tahu bunyi huruf hijaiyah dengan media celemek pintar dan huruf hijaiyah , 1 (satu) anak (10\%) yang mendapat nilai BB, 4 (empat) anak (40\%) mendapat nilai $\mathrm{MB}$, dan 5 (lima) anak (50\%) mendapat nilai BSH.

Pada aspek penilaian kemampuan anak mencari huruf hijaiyah sesuai gambar dengan media celemek pintar, 1 ( satu ) anak(10\%) yang mendapatkan nilai BB, 5 (lima) anak (50\%) mendapatkan nilai MB, dan 4 (empat) anak (40\%) mendapatkan nilai BSH.

Aspek penilaian pada kemampuan anak melengkapi huruf hijaiyah sesuai gambar, 1 (satu) anak (10\%) mendapat nilai BB, 5 (lima) anak (50\%) mendapat nilai MB, dan 4 (empat) anak (40\%) mendapat nilai $\mathrm{BSH}$.

Dari hasil observasi setiap aspek penilaian pada siklus I pertemuan 2 di KB. Aisiyah Tenggarong pada tanggal 15 Maret 2019, dengan jumlah murid yang hadir 10 anak. Aspek pada kemampuan mengenal bentuk huruf hijaiyah dengan media celemek pintar, ada 2 (dua) anak (20\%) mendapat nilai $\mathrm{MB}$, dan 8 (delapan) anak (80\%) mendapat nilai BSH.

Pada aspek penilaian kemampuan anak dalam mengenal dan tahu bunyi huruf hijaiyah dengan media celemek pintar dan huruf hijaiyah, ada 2 (dua) anak (20\%) mendapat nilai MB, 8 (delapan) anak $(80 \%)$ mendapat nilai BSH.

Pada aspek penilaian kemampuan anak mencari huruf hijaiyah sesuai gambar dengan media celemek pintar, ada 4 (empat) anak (40\%) mendapatkan nilai MB, dan 6 (enam) anak (60\%) mendapatkan nilai BSH.

Kemudian pada aspek penilaian pada kemampuan anak melengkapi huruf hijaiyah sesuai gambar, 1 (satu) anak (10\%) mendapat nilai BB, 3 (tiga) anak (30\%) mendapat nilai $\mathrm{MB}$, dan 6 (empat) anak (60\%) 


\section{Tabel . 1 Rekapitulasi Hasil Pencapaian Aspek Penilaian Anak Pada Siklus I Pertemuan 1 dan 2}

\begin{tabular}{|l|l|c|l|}
\hline No & Aspek Penilaian & $\begin{array}{c}\text { Pertemua } \\
\mathrm{n} \\
\text { Ke-1 }\end{array}$ & $\begin{array}{c}\text { Pertemuan } \\
\text { Ke-2 }\end{array}$ \\
\hline 1 & $\begin{array}{l}\text { Mengenal Bentuk Huruf } \\
\text { Hijaiyah }\end{array}$ & $50 \%$ & $80 \%$ \\
\hline 2 & $\begin{array}{l}\text { Mengenal dan Tahu Bunyi } \\
\text { Huruf Hijaiyah }\end{array}$ & $50 \%$ & $80 \%$ \\
\hline 3 & $\begin{array}{l}\text { Mecari Huruf Hijaiyah } \\
\text { sesuai Gambar }\end{array}$ & $40 \%$ & $60 \%$ \\
\hline 4 & $\begin{array}{l}\text { Melengkapi Huruf } \\
\text { Hijaiyah sesuai Gambar }\end{array}$ & $40 \%$ & $60 \%$ \\
\hline $\begin{array}{l}\mathrm{J} \\
\mathrm{u} \\
\mathrm{m} \\
1\end{array}$ & $45 \%$ & $70 \%$ \\
$\mathrm{a}$ \\
$\mathrm{h}$
\end{tabular}

Berdasarkan hasil dari penilaian pada aspek kemampuan anak mengenal huruf hijaiyah pada siklus I pada pertemuan ke 1 dan ke 2, dapat terlihat peningkatan walaupun belum mencapai target maksimal, dengan perbandingan pada pertemuan pertama dengan kemampuan mengenal bentuk huruf hijaiyah 50\% dari 10 anak, kemampuan mengenal dan tahu bunyi huruf hijaiyah 50\% dari 10 anak, kemampuan mencari huruf sesuai gambar $40 \%$, dan kemampuan melengkapi huruf hijaiyah sesuai gambar $40 \%$ dari 10 anak, sehingga mendapat rata-rata peningkatan pada persentasi $45 \%$ peningkatan yang dicapai tiap pada tiap aspek perkembangan.

Pertemuan ke 2 untuk pencapaian kemampuan peningkatan dengan kemampuan mengenal huruf hijaiyah $80 \%$ dari 10 anak, kemampuan mengenal dan tahu bunyi huruf hijaiyah $80 \%$ dari 10 anak, kemampuan mencari huruf hijaiyah sesuai gambar 60\% dari 10 anak, dan kemampuan melengkapi huruf hijaiyah sesuai gambar mencapai $60 \%$ dari 10 anak, rata-rata peningkatan pencapaian kemampuan

pada $70 \%$, dan masih perlu perbaikan agar dapat mencapai mencapai peningkatan kemampuan mengenal huruf hijaiyah secara maksimal.

Hasil dari setiap aspek penilaian pada siklus II pertemuan ke 1 di KB. Aisiyah Tenggarong pada Kelompok Besar dengan jumlah murid 10 anak. Pada aspek kemampuan anak mengenal bentuk huruf hijaiyah dengan media celemek pintar, ada 1 (satu) anak (10\%) mendapat nilai MB, dan 9 (sembilan) anak (90\%) mendapat nilai $\mathrm{BSH}$.

Pada aspek penilaian kemampuan anak dalam mengenal dan tahu bunyi huruf hijaiyah dengan media celemek pintar dan huruf hijaiyah ada, 2 (dua) anak (20\%) mendapat nilai MB, 8 (delapan) anak $(80 \%)$ menfapat nilai BSH.

Pada aspek penilaian kemampuan anak menunjukan huruf hijaiyah sesuai gambar dengan media celemek pintar, ada 4 (empat) anak (40\%) mendapatkan nilai MB, dan 6 (enam) anak (60\%) mendapatkan nilai BSH.

Aspek penilaian pada kemampuan anak melengkapi huruf hijaiyah sesuai gambar, ada 1(satu) anak (10\%) mendapatkan nilai BB, 3 (tiga) anak (30\%) mendapatkan nilai MB, dan 6 (enam) anak (60\%) mendapatkan nilai BSH. 
Dari hasil Penelitian Tindakan Kelas terhadap kemampuan mengenal huruf hijaiyah dengan menggunakan celemek pintar pada KB. Aisiyah Tenggarong, terjadi peningkatan yang terlihat dari presentasi pada kemampuan mengenal bentuk huruf hijaiyah dengan media celemek pintar, ada 1 (satu) anak (10\%) mendapat nilai MB, dan 9 (Sembilan) anak (90\%) mendapat nilai BSH. Pada aspek penilaian kemampuan

anak dalam mengenal dan tahu bunyi huruf hijaiyah dengan media celemek pintar dan huruf hijaiyah, ada ada 1 (dua) anak (10\%) mendapat nilai MB, dan 9 (Sembilan) anak (90\%) mendapat nilai BSH. Pada aspek penilaian kemampuan anak menunjukan huruf hijaiyah sesuai gambar dengan media celemek pintar, ada 2 (dua) anak (20\%) mendapatkan nilai MB, dan 8 (delapan) anak (80\%) mendapatkan nilai BSH. Kemudian pada aspek penilaian pada kemampuan anak melengkapi huruf hijaiyah sesuai gambar, 1 (satu) anak (10\%) mendapat nilai BB, 1 (satu) anak (10\%) mendapat nilai $\mathrm{MB}$, dan 8 (delapan) anak $(80 \%)$ mendapat nilai $\mathrm{BSH}$.
Tabel . 2 Rekapitulasi Hasil Pencapaian Aspek Penilaian Anak Pada Siklus II Pertemuan 1 dan 2

\begin{tabular}{|l|l|l|l|}
\hline No & Aspek Penilaian & $\begin{array}{l}\text { emu } \\
\text { an } \\
\text { Ke- } \\
1\end{array}$ & $\begin{array}{l}\text { emu } \\
\text { an } \\
\text { Ke- } \\
2\end{array}$ \\
\hline 1 & Mengenal Bentuk Huruf Hijaiyah & $90 \%$ & $90 \%$ \\
\hline 2 & $\begin{array}{l}\text { Mengenenal dan Tahu Bunyi } \\
\text { Huruf Hijaiayh }\end{array}$ & $80 \%$ & $90 \%$ \\
\hline 3 & $\begin{array}{l}\text { Mencari Huruf Hijaiyah sesuai } \\
\text { Gambar }\end{array}$ & $60 \%$ & $80 \%$ \\
\hline 4 & $\begin{array}{l}\text { Melengkapi Huruf Hijaiyah } \\
\text { sesuai Gambar }\end{array}$ & $60 \%$ & $80 \%$ \\
\hline Jumlah & $72 \%$ & $85 \%$ \\
\hline
\end{tabular}

Pada pertemuan tahap ini peningkatan kemampuan anak berkembang dengan sangat baik, dapat dilihat pada table observasi, walau masih ada ditemukan satu anak yang masih belum berkembang pada aspek melengkapi huruf hijaiyah sesuai gambar, untuk itu perlu adanya pendekatan inten terhadap satu anak yang belum berkembang agar dapat mencapai perkembangnnya secara optimal. Melalui sebuah aktivitas ini maka anak mendapatkan kemampuan mengenal huruf hijaiyah berdasarkan pengalaman belajarnya. Pada keseluruhan aspek berkembang sesuai harapan (BSH), yaitu mengenal bentuk huruf hijaiyah, mengenal dan tahu bentuk dan bunyi huruf hijaiyah, menunjuk huruf hijaiyah sesuai gambar, melengkapi huruf hijaiyah sesuai gambar telah mencapai $85 \%$.

\section{Pembahasan}

Penelitian terhadap penggunaan media celemek pintar dalam meningkatkan kemampuan mengenal huruf hijaiyah anak usia 3-4 tahun dikelompok bermain Aisyiyiah Tenggarong, dari tiap siklus 
dapat dilihat peningkatannya, dari kemampuan anak mengenal bentuk huruf hijaiyah mencapai mengenal dan tahu bunyi huruf hijaiyah mampu mencari huruf hijaiah sesuai melengkapi huruf hijaiyah sesuai gambar, yang terlihat dari hasil penelitian dari siklus I dan II pada tiap pertemuan.

Tabel . 3 Presentase Peningkatan Penggunaan Media Celemek Pintar Dalam Meniningkatkan Kemampuan Mengenal Huruf Hijaiyah Anak Usia 3-4 Tahun Sesudah Pelaksanaan Tindakan Kelas Pada Setiap Siklus I dan II

\begin{tabular}{|l|l|c|c|}
\hline No & \multicolumn{1}{|c|}{ Aspek Penilaian } & $\begin{array}{c}\text { SIKLUS } \\
\text { I }\end{array}$ & $\begin{array}{c}\text { SIKLUS } \\
\text { II }\end{array}$ \\
\hline 1 & $\begin{array}{l}\text { Mengenal Bentuk Huruf } \\
\text { Hijaiyah }\end{array}$ & $80 \%$ & $90 \%$ \\
\hline 2 & $\begin{array}{l}\text { Mengenenal dan Tahu Bunyi } \\
\text { Huruf Hijaiayh }\end{array}$ & $80 \%$ & $90 \%$ \\
\hline 3 & $\begin{array}{l}\text { Mencari Huruf Hijaiyah } \\
\text { sesuai Gambar }\end{array}$ & $60 \%$ & $80 \%$ \\
\hline 4 & $\begin{array}{l}\text { Melengkapi Huruf Hijaiyah } \\
\text { sesuai Gambar }\end{array}$ & $60 \%$ & $80 \%$ \\
\hline Jumlah & $70 \%$ & $85 \%$ \\
\hline
\end{tabular}

Berdasasarkan tabel diatas merupakan data yang diperoleh dari siklus I dan II terlihat persentase yang menggambarkan adanya peningkatan dari penggunaan media celemek pintar dalam meningkatkan kemampuan mengenal huruf hijaiyah anak usia 3-4 tahin di kelompok bermain Aisyiyah. Pada siklus I nilai rata - rata mencapai $70 \%$ dan pada Siklus II $85 \%$.

Media celemek pintar digunakan sebagai upaya meningkatkan kemampuan anak mengenal huruf hijaiyah, media merupakan APE yang dapat menjadi sumber belajara bagi anak, Kusumaningtyas $(2014 ; 6)$ mengatakan bahwa APE harus mampu membantu pertumbuhan seluruh perkembangan anak dari nilai agama dan moral, bahasa, kognitif, fisik motorik, sosial emosional, seni, APE juga harus mampu mendorong aktivitas bagi anak serta mampu memunculkan respon bagi anak untuk terlibat secara langsung. Jadi Media celemek pintar merupakan APE yang dapat meningkatkan kemampuan mengenal huruf hijaiyah pada anak usia 3-4 tahun, melalui kegiatan mengenal mengenal bentuk huruf hijaiyah mencapai mengenal dan tahu bunyi huruf hijaiyah mampu mencari huruf hijaiah sesuai melengkapi huruf hijaiyah sesuai gambar, melalui aktifitas keterlibatan langsung anak sehingga anak akan semakin mengenal.

Observasi yang peneliti lakukan menggunakan media celemek pintar sebagai solusi untuk meningkatkan kemampuan mengenal huruf hijaiyah pada anak, kemampuan dalam kamus bahasa adalah suatu kebiasaan atau kesanggupan seseorang secara individu, dengan membuat suatu perencanaan dari RPPM, RPPH hingga lembar observasi pencapaian perkembangan anak.

Ketercapaian maskimal dalam penggunaan media celemek pintar dalam meningkatkan kemampuan mengenal huruf hijaiyah pada anak usia 4-5 tahun di Kelompok Bermain Aisyiyah Tenggarong, dapat digambarkan dengan diagram sebagai berikut :

\section{KESIMPULAN}

Berdasarkan hasil penelitian tindakan kelas yang telah dilakukan peneliti di KB. Aisiyah Tenggarong melalui siklus I dan siklus II, analisis hasil 
dan pembahasan dapat disimpulkan bahwa penggunaan media celemek pintar dalam meningkatkan kemampuan mengenal huruf hijaiyah pada anak usia 3-4 tahun, secara keseluruhan telah mengalami peningkatan yang baik disetiap aspek penilaian. Adapun yang menjadi aspek dalam penelitian adalah kemampuan anak mengenal bentuk huruf hijaiyah, mengenal dan tahu bunyi huruf hijaiyah, mampu menunjuk huruf hijaiyah sesuai gambar, dan mampu melengkapi huruf hijaiyah sesuai gambar.

Media celemek pintar dapat digunakan sebagai sumber belajar anak yang dapat dikembangkan sebagai upaya menigkatkan kemampuan tiap aspek perkembangan anak, yang dapat disesuaikan dengan tahapan perkembangan usia anak. Meningkatkan kemampuan mengenal huruf hijaiyah merupakan sutau upaya mengembangkan 6 (enam) aspek pada anak yaitu Nilai agama dan moral, sosial emosional, kognitif, bahasa, fisik motorik dan seni, sesuai yang tertuang pada permen 137/2013. Dalam penerapan penggunaan media celemek pintar untuk meningkatkan kemampuan mengenal huruf hijaiyah pada anak, guru terlebih dahulu memberikan contoh dan membantu anak yang masih perlu bantuan, dan guru selalu merubah strategi pendekatan agar anak dapat lebih aktif dalam mengikuti kegiatan. Peningkatan pada setiap aspek dapat dilihat pada lembar observasi setiap siklus dan hasil rekapitulasi aspek penilaiannya. Secara keseluruhan setiap aspek meningkat dapat dilihat pada tabel grafik peningkatan.

\section{DAFTAR PUSTAKA}

Arikunto, S.2011. Dasar-Dasar Evaluasi Pendidikan Edisi 1. Bumi Aksara.Jakarta

Aqib, dkk, 2015. Penelitian Tindakan Kelas SD, Sejuta Buku. Yogyakarta

Fatimah. 2011. Menciptakan Bahan Ajar Yang Berpusat Pada Anak. Jakarta: CRI Indonesia.

Ismail, Andang. 2009. Education Games: Panduan Praktis Permainan Yang Menjadikan Anak Anda Cerdas, Kreatif, dan Saleh. Yogyakarta: Pro U Media.

Mulyasa.2012. Manajemen PAUD, Bandung. PT. Remaja Rosdakarya.

Nila Kusumaningtyas, 2014. Alat Permainan Edukatif Untuk Pendidikan Anak Usia Dini,Delacita, Karawang

Nurani, Yuliani. 2012. Konsep Dasar Pendidikan Anak Usia Dini. Jakarta : PT Indeks

Nurlaela. 2009. Permainan Kreatif Untuk Memotivasi Anak. Jakarta: Pustaka Bina Swadaya.

Reni Akbar-Hawadi.2010, Psikologi Perkembangan Anak,Jakarta. Grasindo.

Suyadi. 2010. Pedoman Pembelajaran dan manajemen Berbasis Sekolah di Taman Kanak-kanak. Jakarta: BP Cipta Jaya.

Tadkirotun, Mudfiroh. 2012. Pengembangan Kecerdasan Majemuk. Tangeran : Universitas Terbuka. 